10IKC-275

\title{
ABRASION OF DIAMOND: AN EXPERIMENTAL STUDY AND FIELD EVIDENCE
}

\author{
Afanasiev V.P., Pokhilenko N.P. \\ Institute of Geology and Mineralogy, SB RAS, Novosibirsk, Russia
}

\section{INTRODUTION}

Although being exceptionally hard, diamond shows signature of abrasion in some placers. The abrasion degrees range from very low expressed as defects in crystal edges and tips to very high in which crystals become rounded to ovals and their edges are rounded off (Afanasiev et al., 2010). There are two questions arising in this respect that concern with (i) behavior of indicator minerals while they experience abrasion together with diamonds and (ii) abrasion conditions.

These issues were investigated through testing abrasion strengths of indicator minerals and diamond in laboratory experiments and modeling the formation conditions of placers that bear rounded diamonds.

\section{EXPERIMENTAL STUDIES}

The abrasion tests were performed on an ultrasonic dispersant at $22 \mathrm{KHz}$. Grains (2-3 g) of pyrope and magnesian ilmenite were placed in a cylindrical steel container together with eight diamonds, namely, four colorless octahedral crystals or their fragments, one colorless dodecahedron, a yellow cuboid, and a crystal of variety VII according to Orlov's (1984) classification, which was a high-defect aggregate of dodecahedra with many fluid inclusions. The minerals were immersed in water and ultrasonically forced to move whereby they experienced abrasion as a result of high-energy collisions with one another and with the cylinder walls. Altogether 29 tests were performed of 132 hours total duration. The minerals were weighed and photographed after each test.

For the time of the experiment, ilmenite almost disappeared while pyropes lost $75 \%$ of their original weight and acquired spherical or oval shapes (Figs, 1,2). The diamond crystals were abraded only slightly at sharp edges and tips, which was noticeable on close examination only; no weight loss was recorded at instrument precision $\pm 0.01 \mathrm{mg}$. Abrasion was better evident in octahedra and their fragments whereas the cuboids and the variety VII crystal demonstrated high abrasion strengths, possibly owing to their fibrous and thus more "viscous" structure.

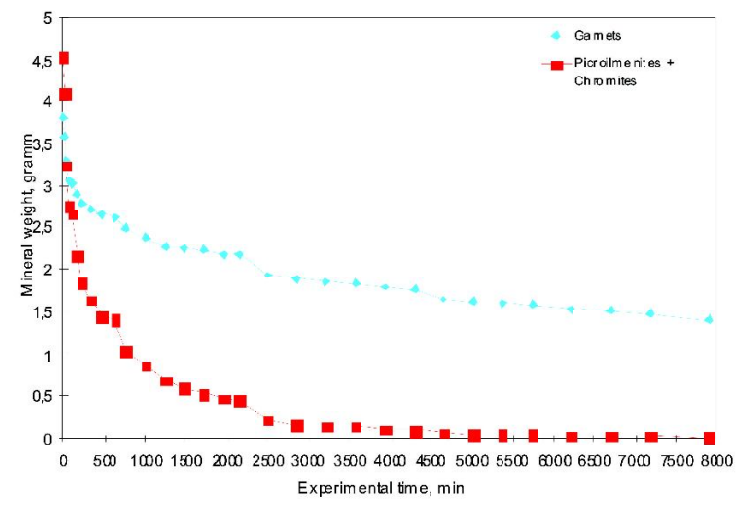

Fig. 1. Weight loss in kimberlite indicator minerals (pyropes, magnesian ilmenites+chromites). 


\section{$10^{\text {th }}$ International Kimberlite Conference, Bangalore - 2012}
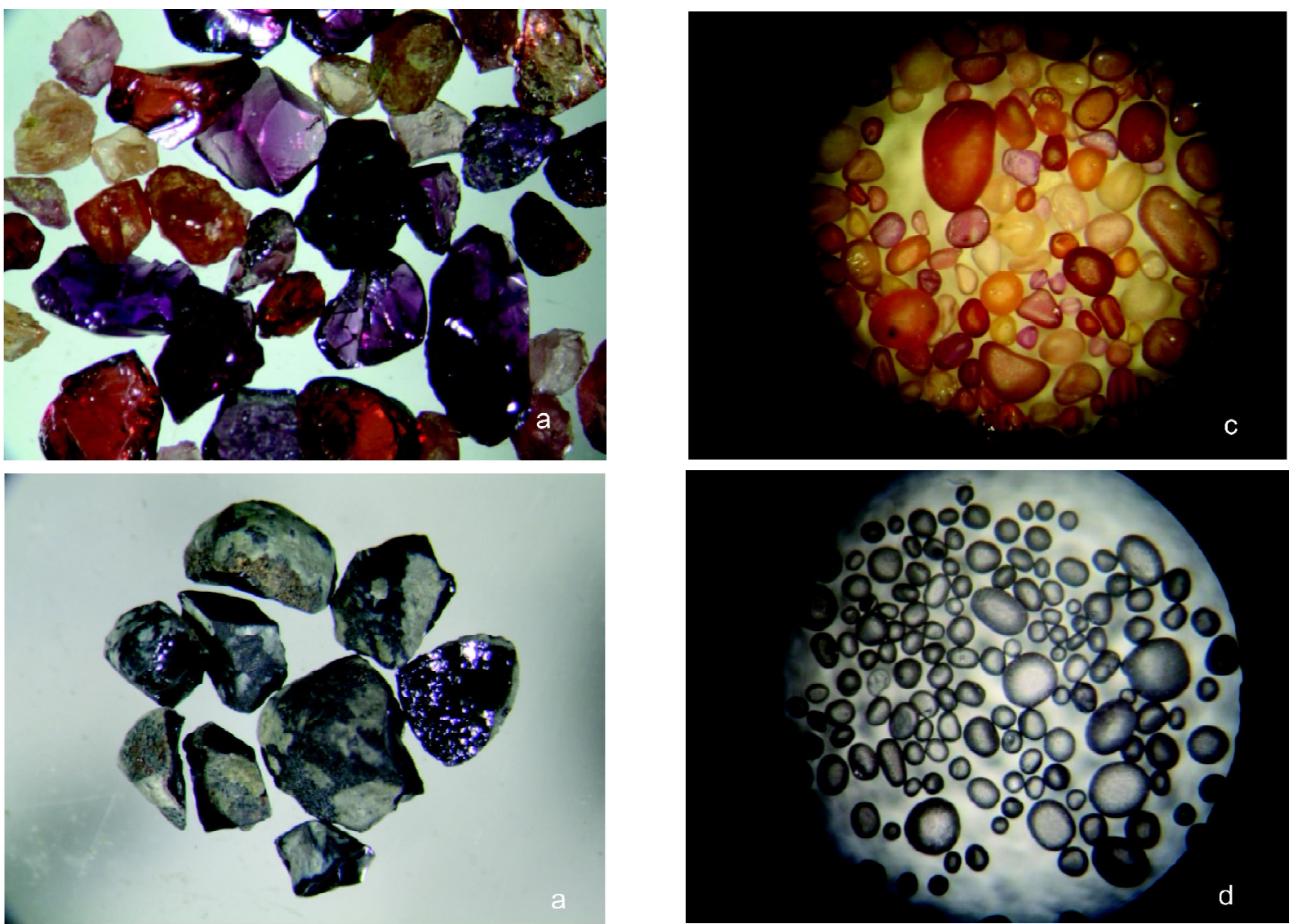

Fig. 2. Pyropes and ilmenites at the beginning of the experiment $(a, b)$ and after 4305 min of ultrasonic treatment $(c, d)$. $a$ and $c$ are pyropes; $b$ and $d$ are ilmenites. Magn. $\times 16$.

\section{DISCUSSION}

The results of the experiments prompt that abrasion of diamond is controlled by the conditions of dispersal during placer formation. Diamond in continental placers that originate from commercial primary deposits and contain a complete assemblage of kimberlite indicator minerals bears no abrasion signature, while kimberlite indicator minerals are abraded to low or medium degrees. The examples are the placers Vodorazdelnye Galechniki (Russian for Watershed Pebbles) or Novinka (Novelty) near Mirny city, or placers near the Nakyn field in Yakutia. In marine (coastal) placers, pyropes are strongly rounded, diamonds show minor abrasion, and ilmenite is fully eliminated (e.g., placers Tarydak in Krasnoyarsk region, Kyutyungde and Almadzha in Yakutia). There are placers in which diamonds are abraded to different degrees, from weak but well evident to medium or strong (Ural, Kalimantan, Burma, southeastern Australia, placers of Brazil, Africa, etc.) while indicator minerals are absent.

Judging by what is known from the reported experiments, one may infer that all indicator minerals which formerly coexisted with diamond in those placers have been eliminated by abrasion during dispersal.

According to a study of dispersal conditions, diamond can reach high roundness degrees only in a hard abrasive environment provided by high hydrodynamic activity. This occurs in coastal swash zones upon metamorphic or igneous bedrock with 


\section{0 $^{\text {th }}$ International Kimberlite Conference, Bangalore - 2012}

clastic material of the same composition, which is a setting typical of Precambrian rather than Phanerozoic time.

Rounded diamonds can fall into young placers either when old placers in exposed inliers of Precambrian basement become eroded or through intermediate Phanerozoic placers. The latter is, for instance, the case of Kalimantan where the intermediate placers are Mesozoic. On redeposition, old diamonds may mix with indicator minerals from Phanerozoic kimberlites, including those from barren ones. As a result, there arises a paradox: the indicator minerals evidence that kimberlites are poor or barren while diamonds are abundant. For example, there are commercial placers under development in northeastern Siberia where all discovered kimberlites show very low or zero diamond contents. Indicator minerals from the area do not show signature of economic kimberlite occurrences while up to $50 \%$ of diamonds are strongly abraded, which attests Precambrian ages of the primary deposits (Afanasiev et al., 2011).

\section{CONCLUSION}

Experiments on abrasion of diamond and kimberlite indicator minerals have shown that at the point when pyropes reach high roundness degrees, magnesian ilmenites become fully eliminated while diamonds bear very weak abrasion signature.

Assemblages in which diamonds exhibit weak (though evident) or heavier abrasion degrees may be monomineral and lack indicator minerals because the latter become abraded almost to zero.

Strongly abraded diamonds may very likely come from Precambrian sources and fall into younger placers as thePrecambrian ones are being eroded.

\section{References}

Afanasiev V.P., Zinchuk N.N., Pokhilenko N.P. (2010) Mineralogy for Diamond Exploration (in Russian). GEO Academic Publishers, Novosibirsk, 650 pp. Afanasiev V.P., Lobanov S.S., Pokhilenko N.P., Koptil V.I., Mityukhin S.I.,

Gerasimchuk A.V., Pomazanskii B.S., Gorev N.I. (2011) Polygenesis of diamonds in the Siberian Platform. Russian Geology and Geophysics 52 (3), (335-353) 259-274.

Orlov, Yu.L. (1984) 